\title{
Prehospital management of burns requiring specialized burn centre evaluation: a single physician-based emergency medical service experience
}

\author{
Ludovic Maudet ${ }^{1,2,3^{*}}$ (D), Mathieu Pasquier ${ }^{1,2}$, Olivier Pantet ${ }^{1,4}$, Roland Albrecht ${ }^{5}$ and Pierre-Nicolas Carron ${ }^{1,2}$
}

\begin{abstract}
Background: Emergency medical services regularly encounter severe burns. As standards of care are relatively wellestablished regarding their hospital management, prehospital care is comparatively poorly defined. The aim of this study was to describe burned patients taken care of by our physician-staffed emergency medical service (PEMS).

Methods: All patients directly transported by our PEMS to our burn centre between January 2008 and December 2017 were retrospectively enrolled. We specifically addressed three "burn-related" variables: prehospital and hospital burn size estimations, type and volume of infusion and pain assessment and management. We divided patients into two groups for comparison: TBSA $<20 \%$ and $\geq 20 \%$. We a priori defined clinically acceptable limits of agreement in the small and large burn group to be $\pm 5 \%$ and $\pm 10 \%$, respectively.

Results: We included 86 patients whose median age was 26 years (IQR 12-51). The median prehospital TBSA was 10\% (IQR 6-25). The difference between the prehospital and hospital TBSA estimations was outside the limits of agreement at $6.2 \%$. The limits of agreement found in the small and large burn groups were $-5.3,4.4$ and $-10.1,11$, respectively. Crystalloid infusion was reported at a median volume of $0.8 \mathrm{ml} / \mathrm{kg} / \mathrm{TBSA}$ (IQR $0.3-1.4$ ) during the prehospital phase, which extrapolated over the first $8 \mathrm{~h}$ would equal to a median volume of $10.5 \mathrm{ml} / \mathrm{kg} / \mathrm{TBSA}$. The median verbal numeric rating scale on scene was 6 (IQR 3-8) and 3 (IQR $2-5)$ at the hospital $(p<0.001)$. Systemic analgesia was provided to 61 (71\%) patients, predominantly with fentanyl $(n=59 ; 69 \%)$, followed by ketamine $(n=7 ; 8.1 \%)$. The median doses of fentanyl and ketamine were $1.7 \mathrm{mcg} / \mathrm{kg}$ (IQR 1-2.6) and $2.1 \mathrm{mg} / \mathrm{kg}$ (IQR 0.3-3.2), respectively.

Conclusions: We found good agreement in burn size estimations. The quantity of crystalloid infused was higher than the recommended amount, suggesting a potential risk for fluid overload. Most patients benefited from a correct systemic analgesia. These results emphasized the need for dedicated guidelines and decision support aids for the prehospital management of burned patients.
\end{abstract}

Keywords: Burn injury, Burn size, Emergency medical services, Fluid therapy, Pain management, Prehospital

\footnotetext{
* Correspondence: ludovic.maudet@chuv.ch

${ }^{1}$ Faculty of Biology and Medicine, University of Lausanne, Rue du Bugnon 21, $\mathrm{CH}-1011$ Lausanne, Switzerland

${ }^{2}$ Department of Emergency Medicine, Lausanne University Hospital, Rue du Bugnon 46, CH-1011 Lausanne, Switzerland

Full list of author information is available at the end of the article
}

C C The Author(s). 2020 Open Access This article is licensed under a Creative Commons Attribution 4.0 International License, which permits use, sharing, adaptation, distribution and reproduction in any medium or format, as long as you give appropriate credit to the original author(s) and the source, provide a link to the Creative Commons licence, and indicate if changes were made. The images or other third party material in this article are included in the article's Creative Commons licence, unless indicated otherwise in a credit line to the material. If material is not included in the article's Creative Commons licence and your intended use is not permitted by statutory regulation or exceeds the permitted use, you will need to obtain permission directly from the copyright holder. To view a copy of this licence, visit http://creativecommons.org/licenses/by/4.0/ The Creative Commons Public Domain Dedication waiver (http://creativecommons.org/publicdomain/zero/1.0/) applies to the data made available in this article, unless otherwise stated in a credit line to the data. 


\section{Background}

The incidence of burn injuries is lowering in high-income countries [1]. However, despite prevention efforts, the social and economic costs remain high and individual consequences are serious [2, 3]. Severe burns require specific expertise and significant resources throughout the course of care [4]. Evidence-based medicine literature supporting prehospital recommendations or guidelines is scarce, although critical issues are shared by many, if not all, emergency services [5]. Keeping the victim stable and orienting care towards a specialised unit are the main priorities of prehospital care of burned patients [6], as well as assessing any possible concomitant injury (inhalation injuries, carbon monoxide or cyanide toxicity and trauma) [7, 8]. Oxygenation and sometimes intubation in patients with suspected smoke inhalation or impaired consciousness [9, 10], co-intoxication treatment, analgesia, and protection against hypothermia are indicated on site $[11,12]$. On the other hand, prehospital recommendations are inconsistent regarding the method and accuracy of the estimation of the total burned surface area [13-17], the amount of fluid volume to be infused precociously [18] and the type of analgesia to be administered [19].

In this study, we wanted to analyse the prehospital management of burned patients in a Swiss physicianstaffed emergency medical service (PEMS), focusing on the three following key points: the burned surface area estimation, prehospital fluid administration, and analgesia management.

\section{Methods}

\section{Study setting and design}

The PEMS of the Lausanne University Hospital includes one ground-based emergency resuscitation vehicle and a rescue helicopter from the Swiss Air-Ambulance. These two PEMS teams operate respectively on ground in the Lausanne city $\left(150 \mathrm{~km}^{2}\right)$ and the surrounding area (400 $\mathrm{km}^{2}$ ) for about 400,000 inhabitants, and by air (rescue helicopter) in a mixed urban and countryside area of $5700 \mathrm{~km}^{2}$ for about 1,300,000 inhabitants. The prehospital emergency physicians are all trained in emergency medicine, including experiences in anaesthesiology and intensive care. All benefited from specific theoretical training in the prehospital management of burns. Trained paramedics constituted the initial response on site. Prehospital emergency physicians were dispatched primarily according to specific keywords (in the case of life-threating emergencies) from a single emergency dispatch centre [20] or upon request by the paramedics on site. In our setting, the two analgesic drugs available were fentanyl (Fentanyl-Janssen ${ }^{\circ}, 50 \mathrm{mcg} / \mathrm{ml}$, JanssenCilag AG, Zoug, Switzerland) and racemic ketamine (Ketamin Sintetica ${ }^{\oplus}, 50 \mathrm{mg} / \mathrm{ml}$, Sintetica SA, Mendrisio, Switzerland).
This cohort study was based on the retrospective review of prospectively collected standardized data of the Lausanne PEMS. We screened all missions from January 2008 to December 2017. During this period, the prehospital care of burned casualties by the Lausanne PEMS were homogeneous and guided by specific local recommendations. We included all patients suffering from thermic burn, directly transported by the Lausanne PEMS, and treated at the Lausanne University Hospital Burn Centre, regardless of their age. The Lausanne University Hospital is a tertiary referral hospital receiving 65,000 emergency patients annually, serving a population of 1,500,000 and is considered a Level 1 trauma centre. It is also one of the two burn centers in Switzerland (the other being at Zurich University Hospital) accredited by the European Burn Association. In accordance with federal regulations, severe burns are systematically referred to these specialized centers by every emergency medical service, without direct contribution or validation from burn specialists during the prehospital management. In 2017, the Lausanne University Hospital Burn Centre took care of 82 severe burned adults and children, with an average length of stay in the burn specialized intensive care unit ( 6 beds) of 0.2 day in children and 0.8 day in adults per percentage of TBSA. We excluded chemical or electrical burns and secondary missions (inter-hospital transfers). The Burn Centre database was also consulted to identify patients managed by the Lausanne PEMS and who may have been missed by our initial search strategy and for complementary missing data.

\section{Data collection}

The data collection was approved by the institutional ethical committee (CER-VD N ${ }^{\circ}$ 2016-01433). Data were extracted from the prehospital and hospital electronic records. Patients were aggregated in two groups based on a $20 \%$ TBSA cut-off, which distinguishes large burns ( $\geq 20 \%$ ) from smaller ones $(<20 \%)$. This cut-off is a recognized threshold for beginning an aggressive reanimation and orienting patients in specialized centres [4, 21]. The separation into two subgroups was based on the prehospital TBSA estimation, except in the case of a missing value (5), where the hospital TBSA estimation was considered.

The demographic characteristics collected were age (in years), gender and estimated in-hospital weight (in kilograms). Among the background of injury, domestic burns occurring at home were distinguished from burns occurring during work or leisure activities. The following burn-related acute comorbidities were also collected: facial burn, inhalation injury and carbon monoxide intoxication. 
The type of PEMS (ground-bases vs. helicopter) was collected, as well as the following time intervals: response interval (from dispatch centre alarm to PEMS arrival on scene), on-scene interval (from PEMS arrival to departure) and transport interval (departure from the scene to arrival at hospital) [22]. We defined the prehospital treatment interval as the time interval from PEMS arrival on-scene to hospital arrival. The severity of involvement was coded and reported by the prehospital emergency physician according to the prehospital $\mathrm{Na}$ tional Advisory Committee for Aeronautics (NACA) score [23].

The initial following parameters were recorded onscene and at the hospital: respiratory rate, heart rate, blood pressure, blood oxygen saturation, Glasgow coma score (GCS), and capillary refill time (CRT, defined as abnormal if $>2 \mathrm{~s}$ ).

Our main outcome was to analyse and describe the following three "burn-related" variables: burned surface area estimation, volume of liquid infused during the prehospital treatment interval, and the prehospital analgesia provided.

We also reported the following prehospital interventions: oxygen therapy, tracheal intubation and vascular access.

The prehospital TBSA estimation (based on the rule of nines) reported by the PEMS was compared to the hospital TBSA estimation (based on Lund and Browder chart) reported by the specialist surgeon at the Burn Centre after the first wound treatment session. Only burned surfaces involving second or higher degree were considered for both prehospital and in-hospital TBSA estimation. We used the volume of prehospital infusion together with the patient's weight to calculate the volume infused per kilogram of body weight and TBSA (ml/kg/TBSA). We further used this data with a hypothetical duration of $8 \mathrm{~h}$ to compare the extrapolated volume infused in our prehospital setting to the Parkland formula [24]. Patients of all TBSA estimates were included in this analysis, even though the Parkland formula is generally recommended for burns involving $\geq 20 \%$ TBSA. The pain was assessed and reported using the verbal numeric rating scale (VNRS, ranging from 0 to 10). The doses and route (intravenous, intramuscular or intranasal) of prehospital analgesia were also analysed, and evaluated by body weight $(\mathrm{mcg} / \mathrm{kg}$ for fentanyl and $\mathrm{mg} / \mathrm{kg}$ for ketamine) and compared to the dosages usually recommended for acute analgesia in trauma or burn patients.

Outcome measures included the mortality, considered as the occurrence of death during the acute care period, from prehospital physician arriving on-scene to patient leaving hospital after initial care. We also recorded the severity of injuries according to the Injury Severity Score
(ISS), length (days) of hospital stay and length (days) of intensive care unit (ICU) stay.

\section{Statistical analysis}

We used Stata (Stata/IC 14.2, StataCorp LLC, TX77845, USA) software to perform the statistical analysis. Descriptive statistics included numbers and frequencies for categorical variables and medians and interquartile ranges (25th to 75th percentile) for continuous variables. The chi-square test was used for categorical data comparisons, while non-normally distributed continuous data were tested using the Wilcoxon test. A bilateral $p$ value $<0.05$ was considered to indicate a significant difference. A Bland-Altman plot was used to compare the prehospital and hospital TBSA estimations [25]. We a priori defined clinically acceptable limits of agreement in the small and large burn groups to be $\pm 5 \%$ and $\pm 10 \%$, respectively.

\section{Results}

\section{Characteristics of the study population}

Among the 16,565 PEMS missions screened during the 10-year study period (Fig. 1), we included 86 patients. Patients' characteristics according to the burn severity subgroups are reported in Table 1 . While the burn injury context (mostly domestic accidents) did do not differ between groups, patients suffering large burns were older ( 23 vs. 39 years old; $p=0.031$ ), more prone to suffer from inhalational injury or carbon monoxide intoxication (27\% vs. $65 \% ; p=0.001)$ and had longer PEMS on-scene times (16 vs. $28 \mathrm{~min} ; p<0.001)$. No patient in the study group suffered from major trauma or multiple traumatic injuries (bone or abdomino-thoracic injuries).

The on-scene heart and respiratory rates were higher and the blood oxygen saturation was lower in patients suffering large burns, while this was not the case at hospital admission (Table 2). Overall intubation rate was $24 \%$ (6 (11\%) patients in the small and 15 (48\%) patients in the large burn subgroups) $(p<0.001)$.

Vascular or intraosseous access were done similarly in both subgroups, with an overall occurrence of 64 cases $(75 \% ; p=0.073)$.

\section{Burn-specific assessments and interventions}

Prehospital estimation of the TBSA was reported by the PEMS in 81 of the 86 cases (94\%). The median TBSA was $10 \%$ (IQR 6-25). Fifty-five patients (64\%) suffered from small burns (TBSA < 20\%) and 31 (36\%) patients suffered from large burns (TBSA $\geq 20 \%$ ). On average, prehospital TBSA estimation was slightly less than hospital TBSA estimation, but the medians were not statistically different $(p=0.78)$. The mean difference in the small burns subgroup was $0.5 \%$, whereas it was -0.4 in the large burns subgroup. The limits of agreement 


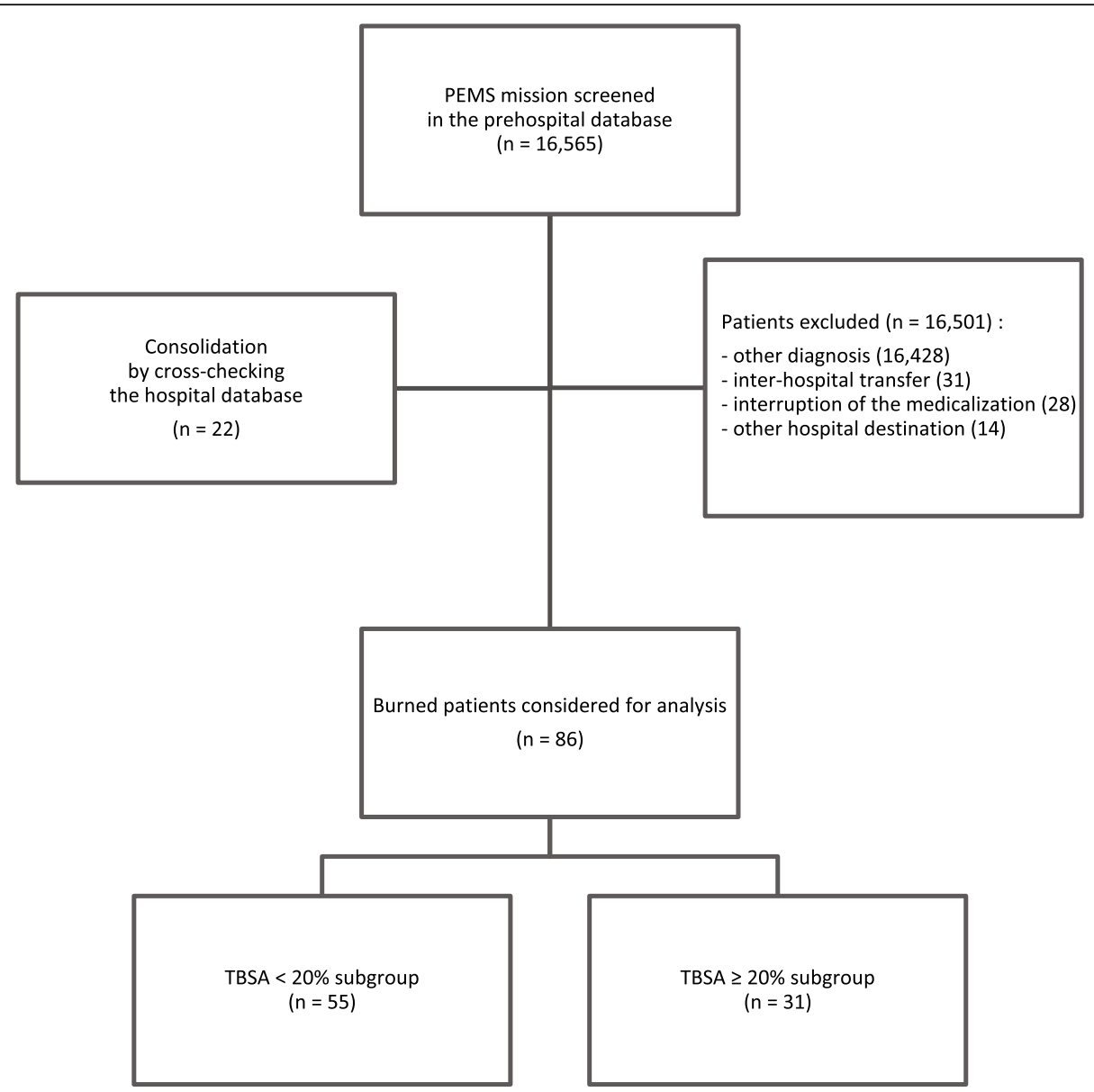

Fig. 1 Flow chart of the case load selection (1 January 2008 to 31 December 2017). The separation into two subgroups is based on the prehospital TBSA estimation, except in the case of a missing value (5), where the hospital TBSA estimation is considered

between the prehospital and hospital TBSA estimations in both groups are shown in Fig. 2. The limits of agreement between the prehospital and hospital TBSA estimations for all patients are available as a supplementary file.

Sixty-four (75\%) patients received intravascular infusion during the prehospital phase (median duration of 33 min; IQR 22-45), all with crystalloids and at a median volume of $0.8 \mathrm{ml} / \mathrm{kg} / \mathrm{TBSA}$ (IQR $0.3-1.4$ ). Extrapolated over the first $8 \mathrm{~h}$, this would equal to a median volume infused of $10.5 \mathrm{ml} / \mathrm{kg} /$ TBSA (Table 3).

An initial pain assessment using the VNRS was available for 59 (69\%) patients. Pain was significantly higher on site than at hospital arrival (median VNRS of 6 (IQR $3-8$ ) vs. 3 (IQR $2-5$ ), $p<0.001$ ). Analgesia was provided in $61(71 \%)$ patients, mostly with fentanyl (59), at a median dose of $1.7 \mathrm{mcg} / \mathrm{kg}$ (IQR 1-2.6) (Table 3). Fentanyl was administered intranasally on $9(10 \%)$ occasions, predominantly $(n=8,89 \%)$ for patients from the small burns subgroup.
The clinical course and outcomes of patients are presented in Table 4 . Seventy-eight out of the 86 patients survived at hospital discharge (91\%). Most non-survivors $(7 / 8,88 \%)$ belonged to the large burns group.

\section{Discussion}

The present study, which included 86 patients, is one of the few to specifically assess the prehospital civilian medical management of burned patients. As in other groups described in Europe, North America and Australia, our patients were predominantly men, of working age, and were injured at home or at work [3, 26, 27]. The agreement between the prehospital and hospital burn size estimations was clinically correct in most cases (within the limits of agreement in $93.8 \%$ of cases). The quantity of crystalloid infused in the first hour was higher than the recommended amount, suggesting a potential risk for fluid overload. Most patients benefited from systemic analgesia (with either fentanyl or ketamine) with a significant reduction in pain upon arrival at the hospital. 
Table 1 Study population and missions characteristics. Data are expressed as numbers and frequencies for categorical variables and medians and interquartile ranges (25th to 75 th percentile). [ = missing values

\begin{tabular}{|c|c|c|c|c|}
\hline & $\begin{array}{l}\text { Study group } \\
n=86(100 \%)\end{array}$ & $\begin{array}{l}\text { TBSA }<20 \% \\
n=55(64 \%)\end{array}$ & $\begin{array}{l}\text { TBSA } \geq 20 \% \\
n=31(36 \%)\end{array}$ & $p$-value \\
\hline Age (years) [0] & $26(12-51)$ & $23(3-50)$ & $39(20-58)$ & $0.031^{*}$ \\
\hline Gender male, n (\%) [0] & $63(73)$ & $43(78)$ & $20(65)$ & 0.169 \\
\hline Weight (kg), median [11] & $65(20-81)$ & $62(14-88)$ & $67(60-75)$ & 0.253 \\
\hline \multicolumn{5}{|l|}{ Injury context, n (\%) [0]: } \\
\hline - Domestic & $50(58)$ & $33(60)$ & $17(55)$ & 0.641 \\
\hline - Work & $18(21)$ & $11(20)$ & $7(23)$ & 0.778 \\
\hline - Leisure & $6(7)$ & $5(9.1)$ & $1(3)$ & 0.305 \\
\hline - Others & $11(13)$ & $5(9.1)$ & $6(19)$ & 0.171 \\
\hline Facial burn, n (\%) [0] & $52(60)$ & $29(53)$ & $23(74)$ & 0.051 \\
\hline Inhalation injury, n (\%) [0] & $35(41)$ & $15(27)$ & $20(65)$ & $0.001^{*}$ \\
\hline Carbon monoxide intoxication, n (\%) [0] & $4(4.7)$ & 0 & $4(13)$ & $0.006^{*}$ \\
\hline \multicolumn{5}{|l|}{ Type of PEMS, n (\%) [0]: } \\
\hline - Ground & $35(41)$ & $23(42)$ & $12(39)$ & 0.381 \\
\hline - Helicopter & $47(55)$ & $32(58)$ & $15(48)$ & 0.778 \\
\hline - Both & $4(4.7)$ & 0 & $4(13)$ & $0.006^{*}$ \\
\hline \multicolumn{5}{|l|}{ Time intervals (minutes), median [0]: } \\
\hline - Response & $15(9-21)$ & $15(10-21)$ & $13(9-20)$ & 0.342 \\
\hline - On-scene & $19(13-30)$ & $16(11-22)$ & $28(17-42)$ & $<0.001^{*}$ \\
\hline - Transport & $11(7-17)$ & $11(6-18)$ & $10(7-16)$ & 0.790 \\
\hline - Prehospital treatment & $33(22-45)$ & 29 (19-39) & $45(24-56)$ & $0.003^{*}$ \\
\hline NACA score, median [0] & $4(3-5)$ & $4(3-4)$ & $5(4-5)$ & $<0.001^{*}$ \\
\hline
\end{tabular}

Table 2 Vitals signs and non-specific interventions. Data are expressed as numbers and frequencies for categorical variables and medians and interquartile ranges (25th to 75 th percentile). [ = missing values

\begin{tabular}{|c|c|c|c|c|}
\hline & $\begin{array}{l}\text { Study group } \\
n=86(100 \%)\end{array}$ & $\begin{array}{l}\text { TBSA }<20 \% \\
n=55(64 \%)\end{array}$ & $\begin{array}{l}\text { TBSA } \geq 20 \% \\
n=31(36 \%)\end{array}$ & $p$-value \\
\hline \multicolumn{5}{|l|}{ Vital parameters on scene: } \\
\hline - Respiratory rate $\left(\mathrm{min}^{-1}\right)[4]$ & $20(16-25)$ & $18(16-22)$ & $25(20-30)$ & $<0.001^{*}$ \\
\hline - $\mathrm{SpO}_{2}(\%)[8]$ & $98(95-100)$ & $98(96-100)$ & $97(92-99)$ & $0.01^{*}$ \\
\hline - Pulse rate $\left(\mathrm{min}^{-1}\right)[7]$ & $100(85-116)$ & $90(80-105)$ & $106(100-120)$ & $<0.001^{*}$ \\
\hline - Systolic blood pressure (mmHg), [13] & $140(90-150)$ & $140(90-150)$ & $140(90-150)$ & 0.735 \\
\hline - Capillary refill time $\geq 2 \mathrm{~s}, \mathrm{n}(\%)[0]$ & $6(7)$ & $4(7.3)$ & $2(6.5)$ & 0.886 \\
\hline - GCS [0] & $15(15-15)$ & $15(15-15)$ & $15(15-15)$ & 0.065 \\
\hline \multicolumn{5}{|l|}{ Vital parameters at ED arrival: } \\
\hline - Respiratory rate $\left(\mathrm{min}^{-1}\right)[29]$ & $16(12-20)$ & $16(13-20)$ & $13(12-21)$ & 0.106 \\
\hline$-\mathrm{SpO}_{2}(\%)[22]$ & $99(96-100)$ & $99(96-100)$ & $99(96-100)$ & 0.949 \\
\hline - Pulse rate $\left(\min ^{-1}\right)[18]$ & $100(80-110)$ & $92(78-105)$ & $103(90-111)$ & 0.061 \\
\hline - Systolic blood pressure (mmHg) [24] & $89(66-98)$ & $84(66-96)$ & $90(62-100)$ & 0.821 \\
\hline - GCS [18] & $15(3-15)$ & $15(15-15)$ & $3(3-15)$ & $<0.001^{*}$ \\
\hline Oxygen therapy, n (\%) [8] & $51(65)$ & $25(51)$ & $26(90)$ & $0.001^{*}$ \\
\hline Tracheal intubation, n (\%) [0] & $21(24)$ & $6(11)$ & $15(48)$ & $<0.001^{*}$ \\
\hline Vascular or intraosseous access, n (\%) [1] & $64(75)$ & $38(69)$ & $26(87)$ & 0.073 \\
\hline
\end{tabular}




\section{a}

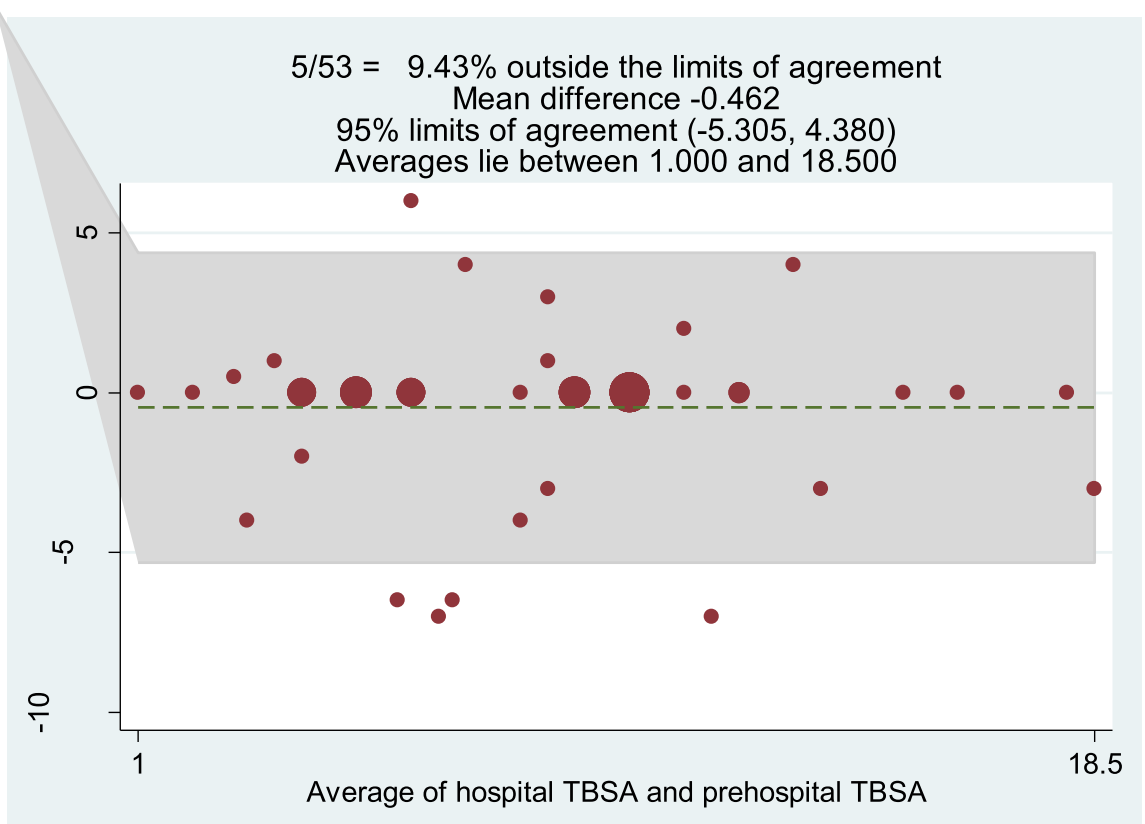

b

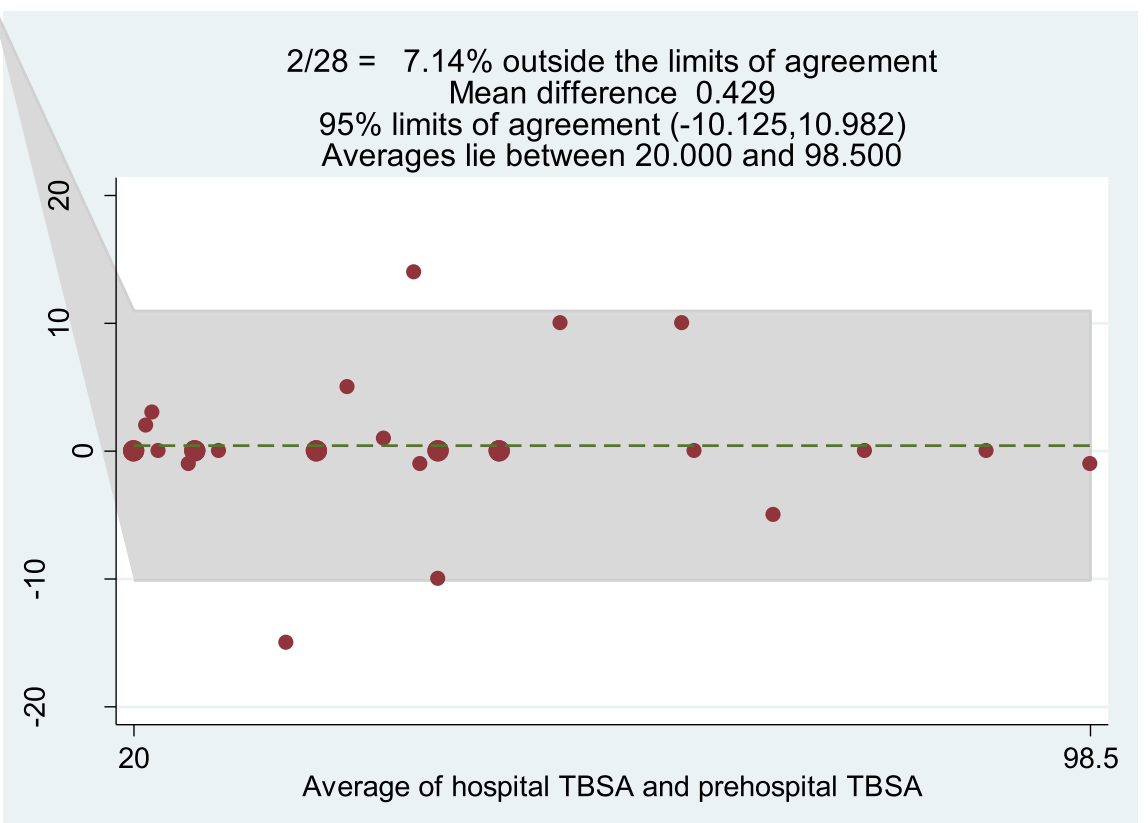

Fig. 2 Bland-Altman analysis of the differences between the hospital and prehospital TBSA estimations in the small (Fig. 2a) and large (Fig. 2b) burns groups. For each comparison, the mean value between the two estimations is plotted against their difference. The mean difference between the hospital and prehospital TBSA estimations were -0.462 for the small and 0.429 for the large burns groups. The lower and upper limits of agreement were -5 and $4 \%$ in the small burns group and -10 and $11 \%$ in the large burns group

We devoted specific attention to the comparison of the prehospital and in-hospital TBSA estimations as accurate assessment of the burn size remains a challenge in the prehospital care of burned patients [14-17]. We mostly used the rule of nines in prehospital care, whereas a Lund and Browder chart was used by the burn specialists. Without any well-established cut-off, we set up $\pm 5 \%$ and $\pm 10 \%$ to be critical differences between 
Table 3 Burn-specific assessment and intervention. Data are expressed as numbers and frequencies for categorical variables and medians and interquartile ranges (25th to 75 th percentile). [ = missing values

\begin{tabular}{|c|c|c|c|c|}
\hline & $\begin{array}{l}\text { Study group } \\
n=86(100 \%)\end{array}$ & $\begin{array}{l}\text { TBSA }<20 \% \\
n=55(64 \%)\end{array}$ & $\begin{array}{l}\text { TBSA } \geq 20 \% \\
n=31(36 \%)\end{array}$ & $p$-value \\
\hline Prehospital (initial) TBSA estimation (in \%) [5] & $10(6-25)$ & $9(5-10)$ & $40(25-50)$ & $<0.001^{*}$ \\
\hline Hospital (final) TBSA measurement (in \%) [1] & $10(6-27)$ & $8.5(4-10)$ & $43(25-55)$ & $<0.001^{*}$ \\
\hline Absolute variation of TBSA [5] & $0(0-3)$ & $0(0-2)$ & $0(0-4)$ & 0.2093 \\
\hline Crystalloid infusion (ml/kg/TBSA) [33] & $0.8(0.3-1.4)$ & $1.3(0.8-1.8)$ & $0.3(0.1-0.4)$ & $<0.001^{*}$ \\
\hline Crystalloid infusion reported to $8 \mathrm{~h}$ (ml/kg/TBSA) [34] & $10.5(3.4-17.4)$ & $15.5(12-25)$ & $2.7(1.4-4)$ & $<0.001^{*}$ \\
\hline Initial pain score (VNRS) [27] & $6(3-8)$ & $5.5(3-7)$ & $8(4-10)$ & $0.039^{*}$ \\
\hline Pain score at ED arrival (VNRS) [51] & $3(2-5)$ & $3(2-5)$ & $4(3-7)$ & 0.154 \\
\hline Analgesia provision, n (\%) [0] & $61(71)$ & $37(67)$ & $24(77)$ & 0.32 \\
\hline Intranasal medication, $\mathrm{n}(\%)[0]$ & $9(10)$ & $8(15)$ & $1(3.2)$ & 0.1 \\
\hline Fentanyl administration, $\mathrm{n}(\%)[0]$ & $59(69)$ & $37(67)$ & $22(71)$ & 0.723 \\
\hline Fentanyl dose (mcg/kg) [0] & $1.7(1-2.6)$ & $1.4(1-1.9)$ & $2.7(1.7-4.7)$ & $0.002^{*}$ \\
\hline Ketamine administration, $\mathrm{n}(\%)$ [0] & $7(8.1)$ & $1(1.8)$ & $6(19)$ & $0.004^{*}$ \\
\hline Ketamine dose $(\mathrm{mg} / \mathrm{kg})[0]$ & $2.1(0.3-3.2)$ & 2.1 & $2.4(0.3-3.2)$ & 1 \\
\hline
\end{tabular}

TBSA estimation for small and large burns, respectively, based on a clinical appreciation. The Bland-Altman analysis showed that $9 \%$ of the small burns and $7 \%$ of the large burns had significant differences between the prehospital and hospital specialized TBSA estimations. The limits of agreement found in the small and large burns groups were $-5.3,4.4$ and $-10.1,11$ respectively, which slightly exceeds the pre-set cut-off. This discrepancy seems to be less than reported by previous studies with similar cut-off ( \pm 5\% TBSA) with 40\% [28] differences (or even more) between estimations [17, 29]. Small burns TBSA estimations are more prone to errors, as previously shown [30], and small burns tend to be overestimated, whereas the larger ones tend to be slightly underestimated. The maximal error in TBSA estimation represented $82 \%$ of the variation from the median TBSA in the small burns subgroup and 35\% in the large burns subgroup. This highlights the impact of errors in TBSA estimation regarding the volume to be infused for small burns as determined by the Parkland formula [24].

Precisely regarding the amount of fluid infused, we found that the median quantity of crystalloids was exaggerated. In the small burns subgroup, which (according to the recommendations $[19,21])$ does not require aggressive volume expansion, we discovered a seven-fold overhead by correcting the volume infused over $8 \mathrm{~h}$ like in the first phase in the Parkland formula. In the large burns subgroup, the infused volume nearly corresponded with the recommendations. This finding is consistent with similar observations made in other studies that described deviation from the Parkland formula from 28 to $61 \%$ of the time [14, 28, 30]. This volume overload reported to the time of intervention is potentially the consequence of the dogma of aggressive filling in the burn and the consequence of the automatic administration of a unit of crystalloid to each patient. This should question our practices in terms of volume expansion, especially for patients suffering small burns, from whom capillary leak should not be predominant but hypothermia could happen [31, 32]. However, the accuracy of very early fluid resuscitation remain, to our knowledge, a topic of debate. Studies already addressing this question in the adult [28] or paediatric [14] population found a trend towards more complications in situations

Table 4 Outcomes. Data are expressed as numbers and frequencies for categorical variables and medians and interquartile ranges (25th to 75 th percentile). [ = missing values

\begin{tabular}{|c|c|c|c|c|}
\hline & $\begin{array}{l}\text { Study group } \\
n=86(100 \%)\end{array}$ & $\begin{array}{l}\text { TBSA }<20 \% \\
n=55(64 \%)\end{array}$ & $\begin{array}{l}\text { TBSA } \geq 20 \% \\
n=31(36 \%)\end{array}$ & $p$-value \\
\hline ISS [21] & $4(1-21)$ & $1(1-4)$ & $25(11-25)$ & $<0.001^{*}$ \\
\hline Death, n (\%) [0] & $8(9.3)$ & $1(1.8)$ & $7(23)$ & $0.001^{*}$ \\
\hline ICU stay, n (\%) [1] & $53(62)$ & $24(44)$ & $29(94)$ & $<0.001$ \\
\hline ICU length of stay (days) [1] & $7(2-27)$ & $4(2-6)$ & $22(7-50)$ & $<0.001^{*}$ \\
\hline Total hospital length of stay (days) [1] & $14(1-28)$ & $5.5(1-18)$ & $30(8-88)$ & $<0.001^{*}$ \\
\hline
\end{tabular}


of inadequate prehospital fluid resuscitation, but no impact on major side effects could not be definitely concluded.

Described as a critical topic and frequent challenge in the acute care of burned patients [33], pain management was reported in almost three-quarters of our caseload, which is quite similar to the $79 \%$ reported in another prehospital study [26]. The median pain on site was more intense for the large burns group (severe pain) as compared with the small burns group (moderate pain). Fentanyl was the most frequently used molecule. Ketamine has been used primarily in large burns (that had more severe pain) and most often (5/7) in combination with fentanyl. The doses of both fentanyl and ketamine correspond to the dosages recommended for acute analgesia or induction and maintenance of sedation [34-36]. Analgesics were used within the recommended doses, and the median pain score at emergency department arrival reached the minor pain category in both subgroups. However, variation stayed high and kept room for improvement. The low rate of initial pain assessment using the VNRS may partially be explained by altered consciousness, as 12 patients had a GCS $<14$.

The helicopter PEMS was proportionally used more for large burns compared to small burns, as already shown in other similar prehospital caseload descriptions $[37,38]$. The cause remains uncertain in our collective but is potentially linked to dispatch criteria and to the nature of the incidents themselves in peri-urban or rural areas. Longer prehospital intervention times were observed in patients with large burns, mainly due to an increase in on-site time, possibly caused by more extensive on-site support (more intravenous or intraosseous access and more intubations). Vital parameters of patients suffering large burns are slightly more pathological than those of patients suffering small burns, as shown elsewhere [26]. As expected, the evolution of these parameters during prehospital management tends to standardize [39], except the systolic blood pressure, which fell in both groups at the measurement at hospital arrival. A pressure drop during burn prehospital treatment has already been reported [27], and the role of opioid analgesic has been evoked [33]. Finally, more largely affected patients had higher NACA and ISS scores. They were more likely to be admitted to the ICU, and their ICU length of stay was longer, as was their hospital stay in general. These findings are similar to those of previous studies [26-28, 37].

\section{Limitations}

This study is limited by its retrospective design, which may have influenced the quality of the data, as well as the presence of some missing data. The rigorous data collection process (standardized prehospital database and systematic review of each prehospital chart by a senior physician) may however counterbalance this limit.

Generalizability of our results may also be limited by the monocentric aspect of our study, which was carried out in a small mixed urban and peri-urban area with a high level of medical care and a prehospital system allowing paramedics a large degree of autonomy. However, this specific setting also has advantages relative to the uniformity and quality of the data, as it comes from an accredited burn centre, including notably standardized outcome adjudication. The relatively small median burned area in our collective constitutes in itself a limitation compared to other settings where dispatch criteria could influence the prevalence of more severe burns in greater numbers. Our small collective also limits the possibility of carrying out sub-group analyzes, for example on inhalation lesions or concomitant poisoning, which prompts further research. The few previous prehospital studies on these topics are indeed retrospective and include a relatively low number of patients. Therefore, our study brings additional scientific knowledge about this very specific and highly specialized type of patient management.

\section{Conclusion}

The present study, which included 86 patients, provides further information about the management of burned patients in the prehospital setting. We found good agreement between the prehospital and hospital burn size estimations in most cases. As the differences between prehospital and hospital TBSA estimations were higher for large burns, these differences were unlikely to have influenced either patients' orientation or outcome. Despite the fair burn size estimation, the quantity of crystalloid infused within prehospital care was higher than the recommended amount, suggesting a potential risk for fluid overload. It was probably of no consequence observed in our collective due to the brevity of the transport to the reference centre. Most patients benefited from systemic analgesia with either fentanyl or ketamine, but documentation of the pain intensity was lacking in about one-third of the patients. These results show that some progress can still be made in PEMS management of burned patients and emphasized the need for dedicated guidelines and modern decision aids to improve the systematic prehospital management of burns.

\section{Supplementary information}

Supplementary information accompanies this paper at https://doi.org/10. 1186/s13049-020-00771-4.

Additional file 1: Figure S1. Bland-Altman analysis of the differences between the hospital and prehospital TBSA estimations. The mean value 
between the two estimations is plotted against their difference. The mean difference between the hospital and prehospital TBSA estimations was -0.154 . The lower and upper limits of agreement were -7.5 and $7.2 \%$, respectively.

\section{Abbreviations}

CRT: Capillary refill time; GCS: Glasgow coma scale; ICU: Intensive care unit; IQR: InterQuartile range; ISS: Injury severity score; NACA score: National advisory committee for aeronautics score; PEMS: Physician-staffed emergency medical service; $\mathrm{SpO}_{2}$ : Peripheral capillary oxygen saturation; TBSA: Total burn surface area; VNRS: Verbal numeric rating scale

\section{Acknowledgements}

None.

\section{Authors' contributions}

Ludovic Maudet: study concept and design, acquisition of data, analysis and interpretation of data, statistical analysis and drafting of manuscript. Mathieu Pasquier: acquisition of data, analysis and interpretation of data, statistical analysis and critical revision of manuscript. Olivier Pantet: acquisition of data and critical revision of manuscript. Roland Albrecht: acquisition of data and critical revision of manuscript. Pierre-Nicolas Carron: study concept and design, acquisition of data, analysis and interpretation of data, statistical analysis and critical revision of manuscript. The author (s) read and approved the final manuscript.

\section{Funding}

This research did not receive any grant from funding agencies in the public, commercial or not-for-profit sectors.

\section{Availability of data and materials}

The dataset analysed during the current study is available from the corresponding author on reasonable request.

\section{Ethics approval and consent to participate}

Data collection, analysis and publication was approved by the institutional ethical committee (CER-NV N²016-01433).

\section{Consent for publication}

Data collection, analysis and publication was approved by the institutional ethical committee (CER-NV N²016-01433).

\section{Competing interests}

The authors report no competing interests relevant to the manuscript.

\section{Author details}

${ }^{1}$ Faculty of Biology and Medicine, University of Lausanne, Rue du Bugnon 21, CH-1011 Lausanne, Switzerland. ²Department of Emergency Medicine, Lausanne University Hospital, Rue du Bugnon 46, CH-1011 Lausanne, Switzerland. ${ }^{3}$ Department of Anesthesiology, Lausanne University Hospital, Ru du Bugnon 46, CH-1011 Lausanne, Switzerland. ${ }^{4}$ Department of Intensive Care Medicine and Burn Centre, Lausanne University Hospital, Rue du Bugnon 46, CH-1011 Lausanne, Switzerland. ${ }^{5}$ Rega - Swiss Air-Rescue, Rega Centre, PO Box 1414, CH-8058 Zurich, Switzerland.

Received: 10 April 2020 Accepted: 28 July 2020

Published online: 20 August 2020

\section{References}

1. GBD 2013 Mortality and Causes of Death Collaborators. Global, regional, and national age-sex specific all-cause and cause-specific mortality for 240 causes of death, 1990-2013: a systematic analysis for the Global Burden of Disease Study 2013. Lancet. 2015;385:117-171. Available from: https://doi. org/https://doi.org/10.1016/S0140-6736(14)61682-2

2. GBD 2017 Causes of Death Collaborators. Global, regional, and national agesex-specific mortality for 282 causes of death in 195 countries and territories, 1980-2017: a systematic analysis for the Global Burden of Disease Study 2017. Lancet. 2018;392(10159):1736-1788. Available from: https://doi. org/10.1016/S0140-6736(18)32203-7
3. Brusselaers N, Monstrey S, Vogelaers D, Hoste E, Blot S. Severe burn injury in Europe: a systematic review of the incidence, etiology, morbidity, and mortality. Crit Care. 2010;14:R188.

4. Berger MM, Shahrokhi S, Jeschke MG. Critical care of thermally injured patient. In: Jeschke MG, Kamolz LP, Sjöberg F, Wolf SE, editors. Handbook of burns. Vienna: Springer Vienna; 2012. p. 203-220. Available from: https://doi. org/https://doi.org/10.1007/978-3-7091-0348-7_14.

5. Allison K. The UK preHospital management of burn patients: current practice and the need for a standard approach. Burns. 2002;28:135-142. Available from: https://doi.org/https://doi.org/10.1016/S0305-4179(01)00083-3.

6. Carter JE, Neff LP, Holmes JH 4th. Adherence to burn center referral criteria: are patients appropriately eing referred? J Burn Care Res. 2010;31:26-30, Available from: https://doi.org/https://doi.org/10.1097/BCR. 0b013e3181cb8efb.

7. Alvarado R, Chung KK, Cancio LC, Wolf SE. Burn resuscitation. Burns. 2009:35:4 14. Available from: https://doi.org/https://doi.org/10.1016/j.burns.2008.03.008.

8. Mlcak R, Cortiella J, Desai MH, Herndon DN. Emergency management of pediatric burn victims. Pediatr Emerg Care. 1998;14:51-4.

9. Cai AR, Hodgman El, Kumar PB, Sehat AJ, Eastman AL, Wolf SE. Evaluating pre burn center intubation practices: an update. J Burn Care Res. 2017;38: e23-e29. Available from: https://doi.org/https://doi.org/10.1097/BCR. 0000000000000457.

10. Romanowski KS, Palmieri TL, Sen S, Greenhaigh DG. More than one third of intubations in patients transferred to burn centers are unnecessary: proposed guidelines for appropriate intubation of the burn patient. J Burn Care Res. 2016;37:e409-e414. Available from: https://doi.org/https://doi.org/ 10.1097/BCR.0000000000000288.

11. Endorf FW, Dries DJ. Burn resuscitation. Scand J Trauma Resusc Emerg Med. 2011;19:69. Available from: https://doi.org/https://doi.org/10.1186/17577241-19-69.

12. Singer AJ, Taira BR, Thode HC Jr, McCormack JE, Shapiro M, Aydin A, et al. The association between hypothermia, prehospital cooling, and mortality in burn victims. Acad Emerg Med. 2010;17:456-459. Available from: https://doi. org/https://doi.org/10.1111/j.1553-2712.2010.00702.x.

13. Smith JJ, Malyon AD, Scerri GV, Burge TS. A comparison of serial halving and the rule of nines as a pre-hospital assessment tool in burns. Br J Plast Surg. 2005;58:957-967. Available from: https://doi.org/https://doi.org/10. 1016/j.bjps.2005.04.007.

14. Baartmans MG, van Baar ME, Boxma H, Dokter J, Tibboel D, Nieuwenhuis MK. Accuracy of burn size assessment prior to arrival in Dutch burn centres and its consequences in children: a nationwide evaluation. Injury. 2012;43: 1451-1456. Available from: https://doi.org/https://doi.org/10.1016/j.injury. 2011.06.027

15. McCulloh C, Nordin A, Talbot LJ, Shi J, Fabia R, Thakkar RK. Accuracy of prehospital care providers in determining total body surface area burned in severe pediatric thermal injury. J Burn Care Res. 2018;39:491-496. Available from: https://doi.org/https://doi.org/10.1093/jbcr/irx004

16. Jose RM, Roy DK, Vidyadharan R, Erdmann M. Burns area estimation-an error perpetuated. Burns. 2004;30:481-482. Available from: https://doi.org/https:// doi.org/10.1016/j.burns.2004.01.019.

17. Berkebile BL, Goldfarb IW, Slater H. Comparison of burn size estimates between prehospital reports and burn center evaluations. J Burn Care Rehabil. 1986;7:411-2.

18. Cartotto R, Greenhalgh DG, Cancio C. Burn state of the science: fluid resuscitation. J Burn Care Res. 2017;38:e596-e604. Available from: https://doi. org/https://doi.org/10.1097/BCR.0000000000000541.

19. Allison K, Porter K. Consensus on the prehospital approach to burns patient management. Emerg Med J. 2004;21:112-4.

20. Dami F, Golay C, Pasquier M, Fuchs V, Carron PN, Hugli O. Prehospital triage accuracy in a criteria based dispatch Centre. BMC Emerg Med. 2015;15:32. Available from: https://doi.org/https://doi.org/10.1186/s12873-015-0058-x.

21. Beerthuizen $G$, Magnette A. European practice guidelines for burn care. Minimum level of burn care provision in Europe. Barcelona: European Burns Association; 2017.

22. Spaite DW, Valenzuela TD, Meislin HW, Criss EA, Hinsberg P. Prospective validation of a new model for evaluating emergency medical services systems by in-field observation of specific time intervals in prehospital care. Ann Emerg Med. 1993;22:638-645. Available from: https://doi.org/https:// doi.org/10.1016/S0196-0644(05)81840-2.

23. Darioli V Taffé P, Carron PN, Dami F, Valloton L, Yersin B, et al. Evaluation of the discriminative performance of the prehospital National Advisory 
Committee for aeronautics score regarding 48-h mortality. Eur J Emerg Med. 2019;26:366-372. Available from: https://doi.org/https://doi.org/10. 1097/MEJ.0000000000000578.

24. Baxter CR. Fluid volume and electrolyte changes of the early postburn period. Clin Plastic Surg. 1974;1:693-703.

25. Bland JM, Altman DG. Statistical methods for assessing agreement between two methods of clinical measurement. Lancet. 1986;327:307-310. Available from: https://doi.org/https://doi.org/10.1016/S0140-6736(86)90837-8.

26. Kallinen $\mathrm{O}$, Koljonen V, Tukiainen E, Randell T, Kirves H. Prehospital care of burn patients and trajectories on survival. Prehosp Emerg Care. 2016;20:97105. Available from: https://doi.org/https://doi.org/10.3109/10903127.2015. 1056895.

27. Hall K, Burns B. A review of the burns caseload of a physician-based helicopter emergency medical service. Emer Med Australas. 2017;29:438443. Available from: https://doi.org/https://doi.org/10.1111/1742-6723.12810.

28. Freiburg $C$, et al. Effects of differences in percent total body surface area estimation on fluid resuscitation of transferred burn patients. J Burn Care Res. 2007;28:42-48. Available from: https://doi.org/https://doi.org/10.1097/ BCR.0B013E31802C88B2.

29. Hammond JS, Ward CG. Transfers from emergency room to burn center: errors in burn size estimate. J Trauma. 1987;27:1161-1165. Available from: https://doi.org/https://doi.org/10.1097/00005373-198710000-00011.

30. Collis N, Smith G, Fenton OM. Accuracy of burn size estimation and subsequent fluid resuscitation prior to arrival at the Yorkshire regional Burns unit. A three year retrospective study. Burns. 1999;25:345-351. Available from: https://doi.org/https://doi.org/10.1016/S0305-4179(99)00007-8.

31. Muehlberger T, Ottomann C, Toman N, Daigeler A, Lehnhardt M. Emergency pre-hospital care of burn patients. Surgeon. 2010;8:101-104. Available from: https://doi.org/https://doi.org/10.1016/j.surge.2009.10.001.

32. Weaver MD, Rittenberger JC, Patterson PD, McEntire SJ, Corcos AC Ziembicki JA, et al. Risk factors for hypothermia in EMS-treated burn patients. Prehosp Emerg Care. 2014;18:335-341. Available from: https://doi. org/https://doi.org/10.3109/10903127.2013.864354.

33. Sullivan SR, Friedrich JB, Engrav LH, Round KA, Heimbach DM, Heckbert SR et al. "opioid creep" is real and may be the cause of "fluid creep." Burns. 2004;30:583-590. Available from: https://doi.org/https://doi.org/10.1016/j. burns.2004.03.002

34. Thomas SH, Shewakramani S. Prehospital trauma analgesia. J Emerg Med. 2008:35:47-57. Available from: https://doi.org/https://doi.org/10.1016/j. jemermed.2007.05.041.

35. Kiavialaitis GE, Müller S, Braun J, Rössler J, Spahn DR, Stein P, et al., Clinical practice of pre-hospital analgesia: an observational study of 20,978 missions in Switzerland. Amer J Emerg Med 2019. Available from https://doi.org/ https://doi.org/10.1016/j.ajem.2019.10.033

36. Dißmann PD, Maignan M, Cloves PD, Gutiérrez Parrés B, Dickerson S, Eberhardt A. A review of the burden of trauma pain in emergency settings in Europe. Pain Ther. 2018;7:179-192. Available from: https://doi.org/https:// doi.org/10.1007/s40122-018-0101-1.

37. Slater H, O'Mara MS, Goldfarb IW. Helicopter transportation of burn patients. Burns. 2002;28:70-72. Available from: https://doi.org/https://doi.org/10.1016/ S0305-4179(01)00069-9.

38. Ahmed A, Van Heukelom P, Harland K, Denning G, Liao J, Born J, et al . Characterizing demographics, injury severity, and intubation status for patients transported by air or ground ambulance to a rural burn center. J Burn Care Res. 2014;35:e151-e158. Available from: https://doi.org/https://doi. org/10.1097/BCR.0b013e31829b3365.

39. Harmsen AMK, Giannakopoulos GF, Moerbeek PR, Jansma EP, Bonjer HJ Bloemers FW. The influence of prehospital time on trauma patients outcome: a systematic review. Injury. 2015;46:602-609. Available from: https://doi.org/https://doi.org/10.1016/j.injury.2015.01.008.

\section{Publisher's Note}

Springer Nature remains neutral with regard to jurisdictional claims in published maps and institutional affiliations.

Ready to submit your research? Choose BMC and benefit from:

- fast, convenient online submission

- thorough peer review by experienced researchers in your field

- rapid publication on acceptance

- support for research data, including large and complex data types

- gold Open Access which fosters wider collaboration and increased citations

- maximum visibility for your research: over $100 \mathrm{M}$ website views per year

At BMC, research is always in progress.

Learn more biomedcentral.com/submissions 